\title{
$\beta$-Aminoethyltrifluoroborates: Efficient Aminoethylations via Suzuki-Miyaura Cross-Coupling
}

\author{
Gary A. Molander ${ }^{*}$ and Fabricio Vargas \\ Roy and Diana Vagelos Laboratories, Department of Chemistry, University of Pennsylvania, \\ Philadelphia, Pennsylvania 19104-6323
}

\begin{abstract}
A set of phenethylamines has been successfully prepared via Suzuki-Miyaura cross-coupling of diverse potassium $\beta$-aminoethyltrifluoroborates with aryl halides. The potassium $\beta$ aminoethyltrifluoroborates were easily prepared via hydroboration of enamine and enamide precursors.
\end{abstract}

Phenethylamines and their structural analogues comprise important substructures of a variety of biologically important compounds including dopamine, tyrosine, amphetamine, and adrenaline. These privileged scaffolds are also widely found as components of alkaloid natural products ${ }^{1}$ and often serve as key building blocks in the synthesis of numerous nitrogencontaining complex molecules. Previous methods to introduce an aminoethyl group into an arene have employed the Friedel-Crafts acylation of activated arenes with $\mathrm{N}$-protected amino acid chlorides, ${ }^{2}$ Heck arylation of $N$-vinyloxazolone followed by hydrogenation, ${ }^{3}$ and crosscoupling reactions involving $\beta$-amino organozinc reagents, which are somewhat unstable to $\beta$-elimination. ${ }^{4}$ Earlier investigations to access these important units also include the direct coupling of $\beta$-aminoethyl organolithiums with aryl- and alkenyl halides. ${ }^{5} \mathrm{~A}$ more broadly applicable Suzuki cross-coupling ${ }^{6}$ approach to this interesting class of compounds has been developed by Overman. ${ }^{7}$ However, although there are distinct advantages of this one-pot $\beta$ aminoethylation procedure in cross-coupling reactions and total synthesis (e.g., the reactions can be performed at room temperature), ${ }^{8}$ there are some limitations as well. In particular, the organoborane reagents prepared in situ via hydroboration of benzyl vinyl carbamate cannot be easily isolated and stored, but must be prepared and utilized on a reaction-by-reaction basis.

By contrast, potassium organotrifluoroborates have been shown to overcome this particular limitation. These salts are unique organoboron compounds, notable for their stability to moisture and air. ${ }^{9}$ They are powders or crystalline solids that are easy to access and handle, and these properties have made them attractive synthetic intermediates. Herein we describe our initial efforts to develop a convenient and practical access to phenethylamines via Suzuki cross-coupling of potassium $\beta$-aminoethyltrifluoroborates with aryl electrophiles.

To initiate studies on the aminoethylation reactions, a hydroboration protocol was employed that mimicked procedures reported by Overman. ${ }^{8}$ Thus, the respective $N$-vinyl substrates 10 were hydroborated using Snieckus' di(isopropylprenyl)borane $\left(i-\mathrm{PP}_{2} \mathrm{BH}\right), 11$ and the resulting organoborane intermediates were treated with an aqueous solution of $\mathrm{KHF}_{2}$ to afford the desired $\beta$-aminoethyltrifluoroborates 1a-e as depicted in Table 1. 
Although organotrifluoroborate 1a has been obtained in excellent yield (Table 1, entry 1), the organotrifluoroborates containing a 7-membered and 5-membered lactam $\mathbf{1 b}$ and 1c (Table 1, entries 2-3) were obtained in lower yields. The Snieckus hydroboration protocol also tolerates nitrogen protecting groups as Boc and Cbz. However, the desired salts $\mathbf{1 d}$ and $\mathbf{1 e}$ were obtained in moderate yields (Table 1, entries 4-5). All of the new potassium $\beta$ -

aminoethyltrifluoroborates were obtained as powders or crystalline white solids that were stored on the benchtop without detectable degradation.

Initially, we focused on optimization of the reaction conditions for the Suzuki cross-coupling of $\beta$-aminoethyltrifluoroborates and aryl electrophiles (Table 2). Thus, 1 a and 4bromobenzonitrile were chosen as representative coupling partners. Based on the optimized cross-coupling reaction conditions reported between alkyltrifluoroborates and aryl bromides, 12 we first conducted the reaction in the presence of different loadings of $\mathrm{PdCl}_{2}$ (dppf)

. $\mathrm{CH}_{2} \mathrm{Cl}_{2}$ using $\mathrm{Cs}_{2} \mathrm{CO}_{3}$ (3 equiv) as base, in a mixture of toluene/ $\mathrm{H}_{2} \mathrm{O}$ (3:1) as solvent (Table 2 , entries 1-3). It was observed that using $5 \mathrm{~mol} \%$ of the catalyst, the desired phenethylamine 2a was obtained in $90 \%$ yield (Table 2, entry 2). Subsequently, systems were tested using 5 mol $\%$ of different palladium sources and ligands (Table 2, entries 4-7), but the desired product was formed in lower yields. The efficiency of $\mathrm{PdCl}_{2}(\mathrm{dppf}) \cdot \mathrm{CH}_{2} \mathrm{Cl}_{2}$ was also evaluated in the presence of different inorganic bases and $\mathrm{Et}_{3} \mathrm{~N}$, as well as in a different solvent $\left[\mathrm{THF} / \mathrm{H}_{2} \mathrm{O}\right.$ (10:1)]. However, in all cases no improvement could be observed (Table 2, entries 8-11).

The optimized conditions were subsequently applied to cross-coupling reactions with electronpoor electrophiles, as depicted in Table 3 . The reaction proceeds with comparable yields when different leaving groups attached to $p$ - $\operatorname{AcPhX}(\mathrm{X}=\mathrm{Br}$, I, OTf $)$ were tested in the cross-coupling reaction (Table 3, entry 2 ). All of the desired phenethylamines were obtained with good to excellent yields (73-90\%) in the presence of a wide variety of functional groups including nitriles, ketones, esters, aldehydes, halides, and nitro groups in the para position. The crosscoupling reaction also tolerates bromides with substituents in the ortho and meta positions, as the corresponding products were afforded in uniform yields (Table 3, entries 9-10).

The introduction of an ethylamine moiety was also evaluated under the same reaction conditions using electron-rich bromides, as shown in Table 4. The coupling products were synthesized in moderate to good yields in the presence of functionalized bromides. Interestingly, comparable yields for the corresponding phenethylamines were obtained when a non-substituted bromide and a sterically hindered bromide were used as coupling partners (Table 4, compare entries 1 and 2). As observed with the electron-poor bromides, substituents located at different positions about the aromatic ring do not seem to show a strong influence in terms of yield for the respective phenethylamines (Table 4, entries 6 and 7).

Next, the scope of the cross-coupling reaction was explored using heteroaryl bromides as coupling partners, as outlined in Table 5. The optimized conditions are quite general, as the present reaction provides the desired products in acceptable yields (Table 5, entries 1-3) and also tolerates different functional groups attached to furan, pyridine, and indole moieties. However, when a thiophene derivative was used, no coupling was observed. This unsatisfactory result prompted us to screen different coupling conditions as well as alternative ligands such as SPhos, XPhos and RuPhos (Figure 1). ${ }^{13}$

After investigating several conditions, 2 mol \% of $\mathrm{Pd}(\mathrm{OAc})_{2}$ and $4 \mathrm{~mol} \%$ of RuPhos (Table 5 , entry 4) showed the best catalytic performance, affording the product in $71 \%$ yield.

Having demonstrated the efficiency of organotrifluoroborate 1a as a convenient aminoethylating agent for aryl- and heteroaryl bromides, we investigated the scope of the method using the $\beta$-aminoethyltrifluoroborates $\mathbf{1 b}$ and $\mathbf{1} \mathbf{c}$. We initially conducted the reaction using $5 \mathrm{~mol} \%$ of $\mathrm{PdCl}_{2}$ (dppf) $\cdot \mathrm{CH}_{2} \mathrm{Cl}_{2}$, but the desired products were not obtained. Based on 
the successful procedure with the thiophene derivative, we used the RuPhos catalytic system, and in this case the phenethylamines $\mathbf{3 a}$ and $\mathbf{3 b}$ were obtained in $78 \%$ and $71 \%$ yields, respectively, as displayed in eq 1 .

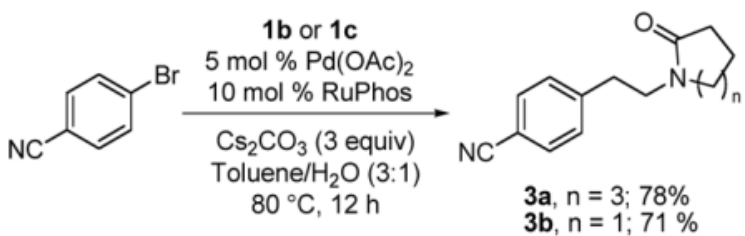

The organotrifluoroborates $\mathbf{1 d}$ and $\mathbf{1} \mathbf{e}$ were also employed as coupling partners in the crosscoupling reaction. The previously optimized conditions were used to couple the corresponding $\beta$-aminoethyltrifluoroborates with 4-bromobenzonitrile, affording the corresponding phenethylamines $\mathbf{4 a}$ and $\mathbf{4 b}$ in good yields as outlined in eq 2 . This coupling is particularly relevant because it provides an easy and efficient alternative to prepare phenethylamines containing free amino groups after appropriate deprotection of the respective Boc and $\mathrm{Cbz}$ protecting groups.

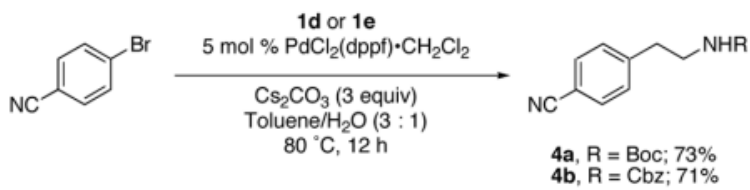

In summary, we have been described an efficient and convenient synthesis of an important class of compounds through the Suzuki-Miyaura cross-coupling reaction. The potassium $\beta$ aminoethyltrifluoroborates, readily obtained as stable crystalline solids in moderate to excellent yields via Snieckus hydroboration with $i-\mathrm{PP}_{2} \mathrm{BH}$, have successfully proven their utility and versatility as useful aminoethylating reagents in the synthesis of a series of phenethylamines. The $\beta$-aminoethylation procedure tolerates diverse functional groups in the organotrifluoroborates as well as in the respective aryl-and heteroaryl electrophiles, affording the desired products in good to excellent yields. The stability of the $\beta$ aminoethyltrifluoroborates recommends them to diversity oriented synthesis, as a variety of these reagents can be prepared and stored indefinitely, awaiting coupling to diverse electrophiles. In this regard, studies directed toward a general method to prepare a wider range of potassium $\beta$-aminoethyltrifluoroborates are underway.

\section{Supplementary Material}

Refer to Web version on PubMed Central for supplementary material.

\section{Acknowledgements}

This work was supported by the CNPq (Conselho Nacional de Desenvolvimento Científico e Tecnológico) (SWE 201094/2005-3). We thank the National Institutes of Health (GM 35249), Amgen, Merck Research Laboratories, and Johnson Matthey for their generous support.

\section{References}

1. (a) Bentley KW. Nat Prod Rep 1999;16:367.Lednicer Mitscher, LA. The Organic Chemistry of Drug Synthesis. 7. Wiley; New York: 1997. 
2. Nordlander JE, Payne MJ, Njoroge FG, Balk MA, Laikos GD, Vishwanath VM. J Org Chem 1984;49:4107.

3. Busacca CA, Johnson RE, Swestock J. J Org Chem 1993;58:3299.

4. (a) Duddu R, Eckhardt M, Furlong M, Knoess HP, Berger S, Knochel P. Tetrahedron 1994;50:2415. (b) Hunter C, Jackson RFW, Rami HK. J Chem Soc, Perkin Trans 1 2000:219. (c) Rilatt I, Caggiano L, Jackson RFW. Synlett 2005:2701.

5. Barluenga J, Montserrat JM, Florez J. J Org Chem 1993;58:5976.

6. For a review of the Suzuki reaction, see: (a) Miyaura N, Suzuki A. Chem Rev 1995;95:2457. (b) Kotha S, Lahiri K, Dhurke K. Tetrahedron 2002;58:9633.

7. Kamatani A, Overman LE. J Org Chem 1999;64:8743.

8. (a) Kamatani A, Overman LE. Org Lett 2001;3:1229. [PubMed: 11348201] (b) Dounay AB, Overman LE, Wrobleski AD. J Am Chem Soc 2005;127:10186. [PubMed: 16028927] (c) Fuchs JR, Funk RL. Org Lett 2005;7:677. [PubMed: 15704923]

9. For the synthesis of organotrifluoroborates see: (a) Vedejs E, Chapman RW, Fields SC, Liu S, Schrimpf MR. J Org Chem 1999;60:3020. (b) Vedejs E, Fields SC, Hayashi R, Hitchcock SR, Powell DR, Schrimpf MR. J Am Chem Soc 1999;121:2460. For reviews of organotrifluoroborate salts, see: (c) Molander GA, Figueroa R. Aldrichimica Acta 2005;38:49. (d) Darses S, Genêt JP. Eur J Org Chem 2003:4313. (e) Molander GA, Ellis N. Acc Chem Res. in press

10. 9-Vinylcarbazole, $N$-vinylcaprolactam and $N$-vinyl-2-pyrrolidone are commercially available; $N$ Boc vinyl carbamate and $N$-Cbz vinyl carbamate were prepared according to the procedures described in the literature (See Supporting Information).

11. Kalinin AV, Scherer S, Snieckus V. Angew Chem Int Ed 2003;42:3399.

12. (a) Molander GA, Ito T. Org Lett 2001;3:393. [PubMed: 11428022] (b) Molander GA, Yun CS, Ribagorda M, Biolatto B. J Org Chem 2003;68:5534. [PubMed: 12839444]

13. (a) Milne JE, Buchwald SL. J Am Chem Soc 2004;126:13028. [PubMed: 15469301] (b) Barder TE, Walker SD, Martinelli JR, Buchwald SL. J Am Chem Soc 2005;127:4685. [PubMed: 15796535] 


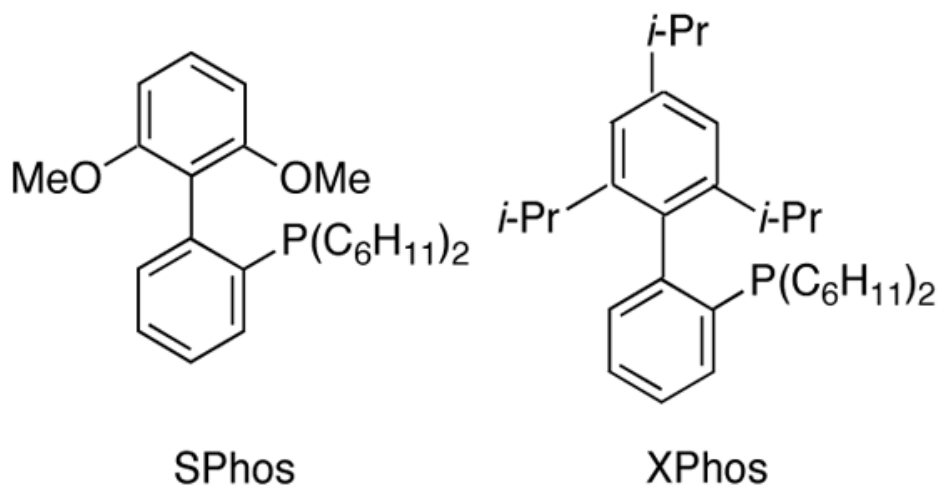

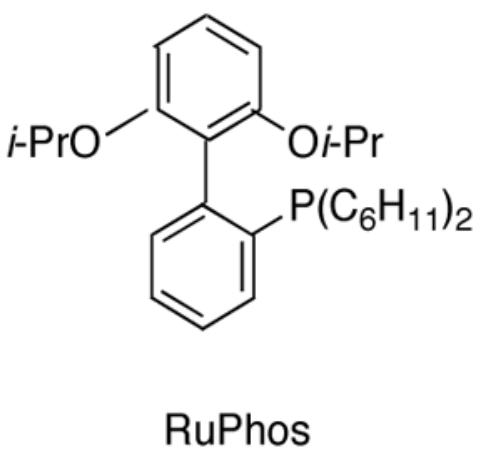

Figure 1.

Buchwald Ligands 
Table 1

Preparation of Potassium $\beta$-Aminoethyltrifluoroborates

entry


Table 2

Optimization of Cross-Coupling Reaction for the Synthesis of 2a
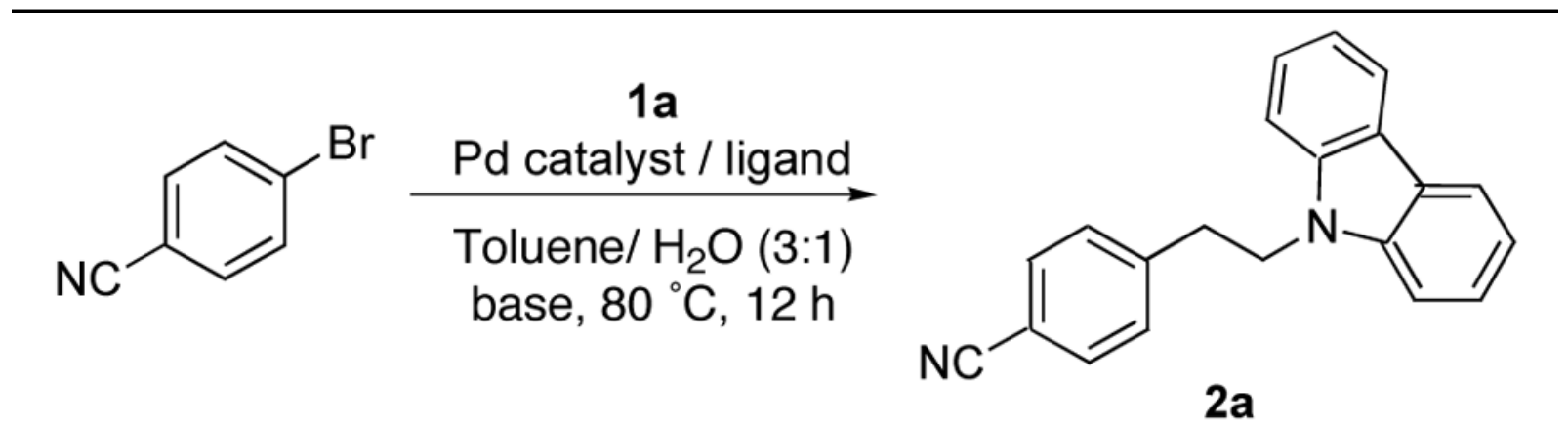

\begin{tabular}{|c|c|c|c|}
\hline entry & catalyst/ligand (mol \%) & base $^{a}$ & $\%$ isolated yield \\
\hline 1 & $\mathrm{PdCl}_{2}(\mathrm{dppf}) \cdot \mathrm{CH}_{2} \mathrm{Cl}_{2}(10)$ & $\mathrm{Cs}_{2} \mathrm{CO}_{3}$ & 84 \\
\hline 2 & $\mathrm{PdCl}_{2}(\mathrm{dppf}) \cdot \mathrm{CH}_{2} \mathrm{Cl}_{2}(5)$ & $\mathrm{Cs}_{2} \mathrm{CO}_{3}$ & 90 \\
\hline 3 & $\mathrm{PdCl}_{2}(\mathrm{dppf}) \cdot \mathrm{CH}_{2} \mathrm{Cl}_{2}(2)$ & $\mathrm{Cs}_{2} \mathrm{CO}_{3}$ & 68 \\
\hline 4 & $\mathrm{Pd}(\mathrm{OAc})_{2} / 2 \mathrm{PPh}_{3}(5)$ & $\mathrm{Cs}_{2} \mathrm{CO}_{3}$ & 78 \\
\hline 5 & $\mathrm{PdCl}_{2} / 2 \mathrm{PPh}_{3}(5)$ & $\mathrm{Cs}_{2} \mathrm{CO}_{3}$ & 56 \\
\hline 6 & $\mathrm{PdCl}_{2}\left(\mathrm{PPh}_{3}\right)_{2}(5)$ & $\mathrm{Cs}_{2} \mathrm{CO}_{3}$ & 72 \\
\hline 7 & $\mathrm{Pd}\left(\mathrm{PPh}_{3}\right)_{4}(5)$ & $\mathrm{Cs}_{2} \mathrm{CO}_{3}$ & 51 \\
\hline 8 & $\mathrm{PdCl}_{2}(\mathrm{dppf}) \cdot \mathrm{CH}_{2} \mathrm{Cl}_{2}(5)$ & $\mathrm{K}_{2} \mathrm{CO}_{3}$ & 69 \\
\hline 9 & $\mathrm{PdCl}_{2}(\mathrm{dppf}) \cdot \mathrm{CH}_{2} \mathrm{Cl}_{2}(5)$ & $\mathrm{K}_{3} \mathrm{PO}_{4}$ & 77 \\
\hline 10 & $\mathrm{PdCl}_{2}(\mathrm{dppf}) \cdot \mathrm{CH}_{2} \mathrm{Cl}_{2}(5)$ & $\mathrm{Et}_{3} \mathrm{~N}$ & 73 \\
\hline 11 & $\mathrm{PdCl}_{2}(\mathrm{dppf}) \cdot \mathrm{CH}_{2} \mathrm{Cl}_{2}(5)$ & $\mathrm{Cs}_{2} \mathrm{CO}_{3}$ & $75^{b}$ \\
\hline
\end{tabular}

$a_{3 \text { equiv }}$

${ }^{b} \mathrm{~A}$ mixture of $\mathrm{THF} / \mathrm{H}_{2} \mathrm{O}(10: 1)$ was used as the solvent. 
Table 3

Cross-Coupling of Potassium $\beta$-Aminoethyltrifluoroborate 1a with Electron-Poor Aryl Bromides

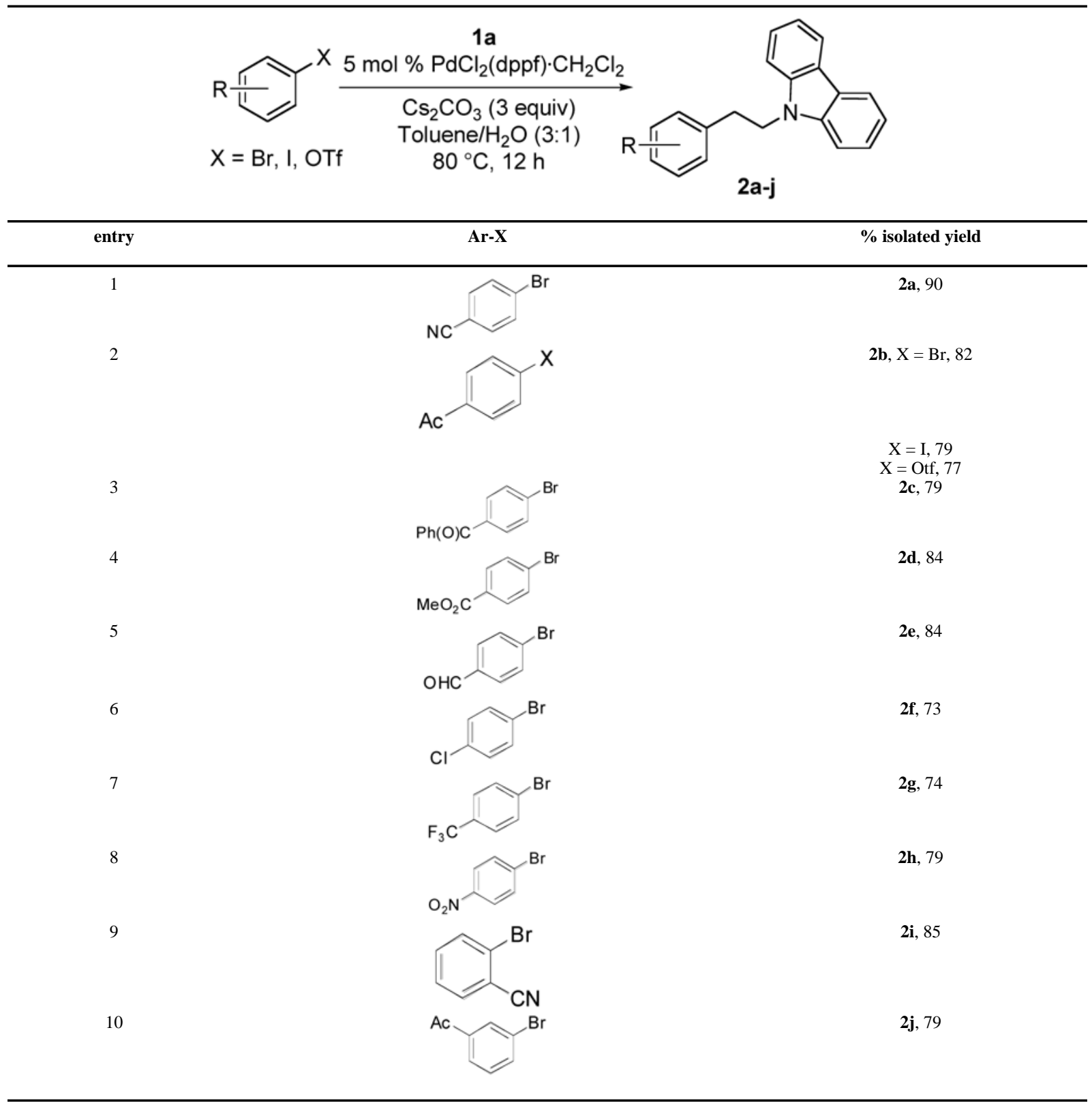


Table 4

Cross-Coupling of Potassium $\beta$-Aminoethyltrifluoroborate 1a with Electron-Rich Bromides

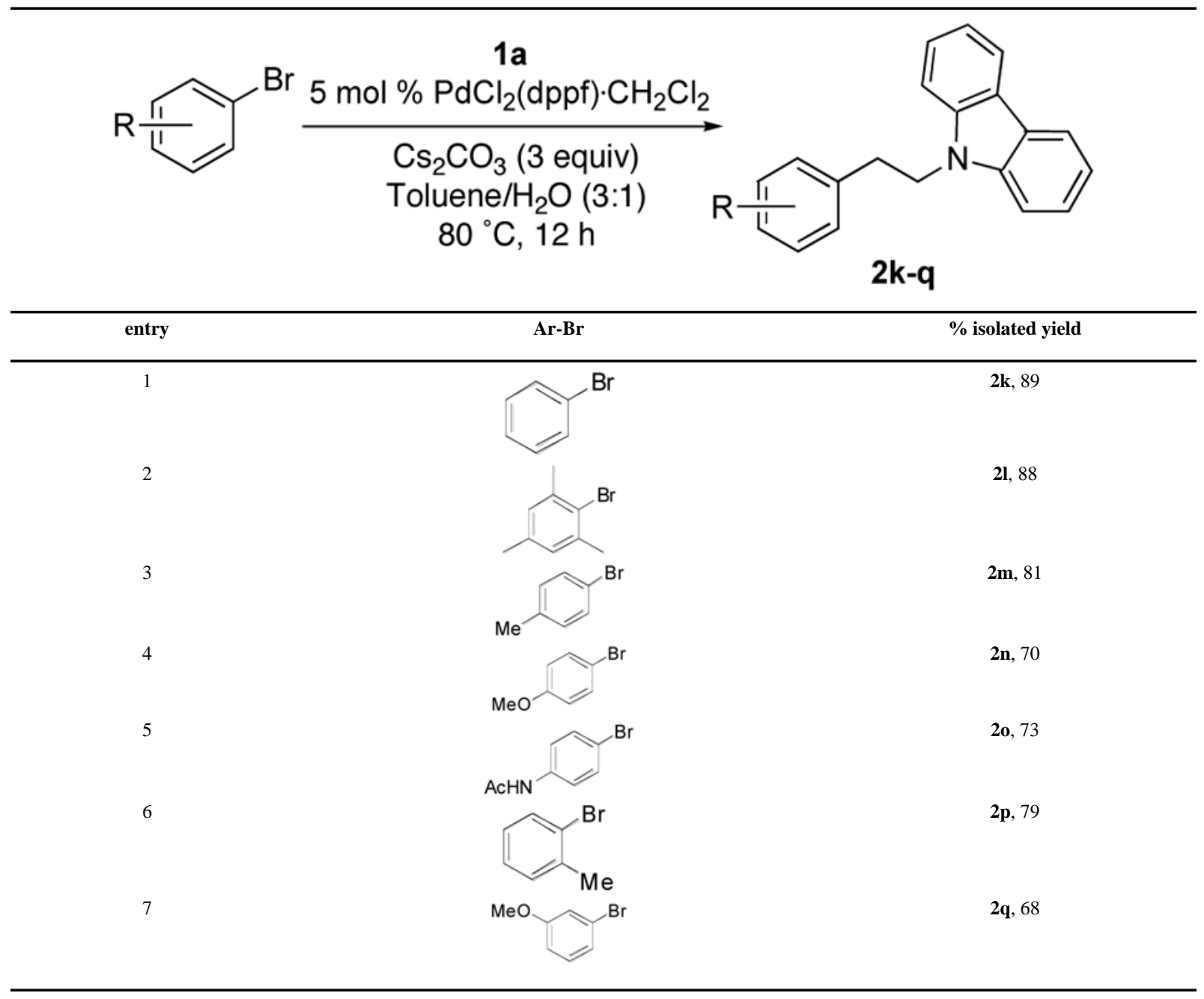


Table 5

Cross-Coupling of Potassium $\beta$-Aminoethyltrifluoroborate 1a with Heteroaryl Bromides

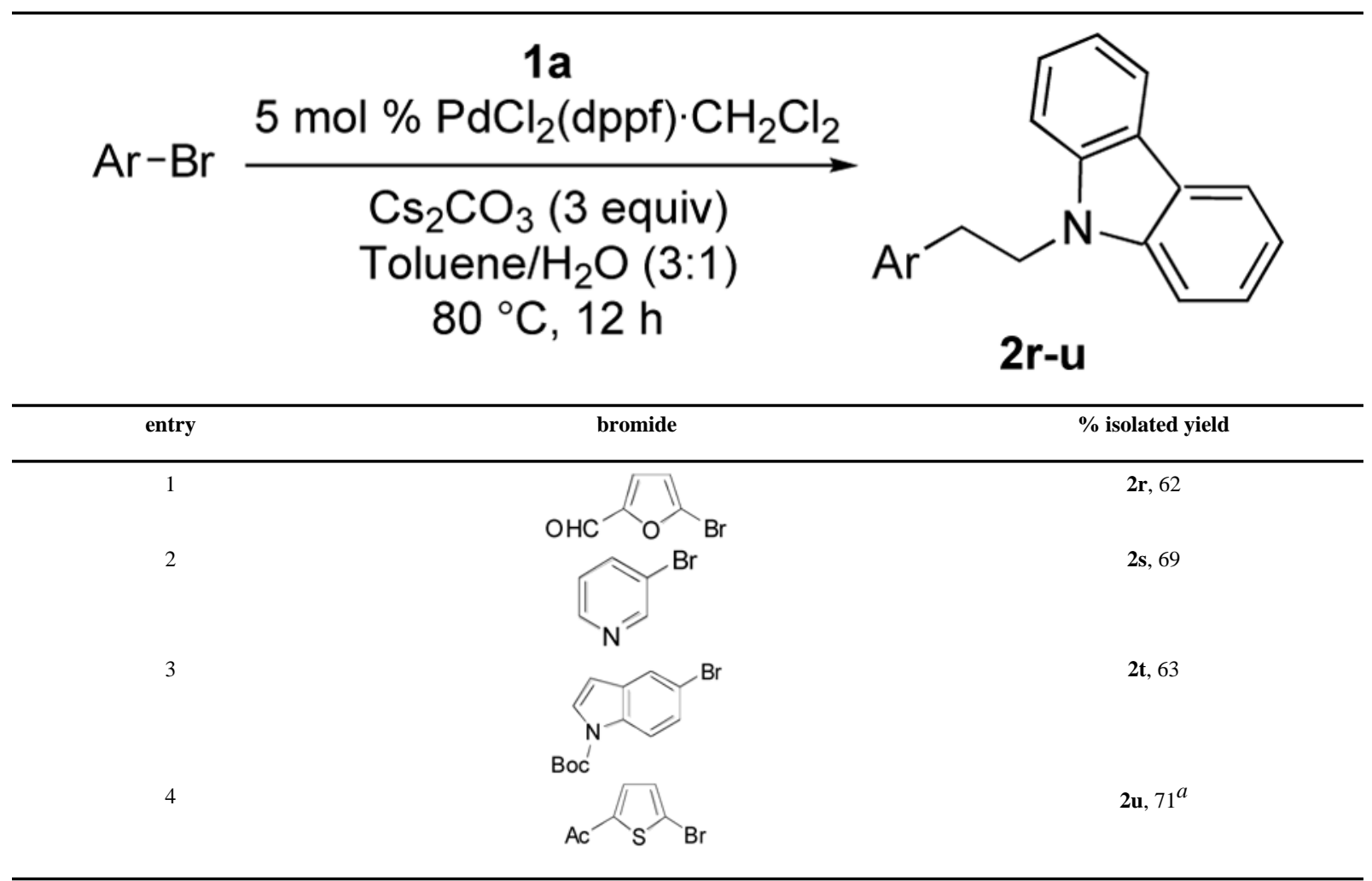

${ }^{a} \mathrm{Pd}(\mathrm{OAc}) 2(2 \mathrm{~mol} \%)$ and RuPhos $(4 \mathrm{~mol} \%)$ were used in the catalytic system. 